\title{
Nurses Providing ANesthesia Not a "LAUghing" MATTER: WhY INDIANA SHOULD NOT OPT OUT OF Federal Physician SuPERVISION OF CERTIFIEd NURSE ANESTHETISTS REQUIREMENTS
}

\author{
Kyle K. Fairchild*
}

I. INTRODUCTION

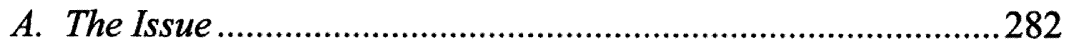

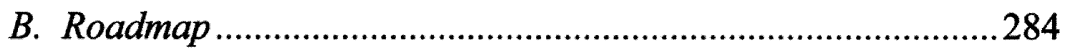

II. HISTORY AND BACKGROUND OF CERTIFIED REGISTERED NURSE

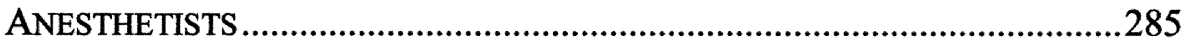

A. History and Development of the Nurse Anesthetist Practice..285

$B$. Educational/Certification Requirements and Statutory

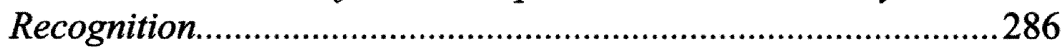

C. Reimbursement of CRNA Service .......................................28

III. ANALYSIS OF RECENT NURSE ANESTHETIST STUDIES.........................290

A. Anesthesiologist Direction and Patient Outcome ....................290

B. Cost Effectiveness Analysis of Anesthesia Providers...............292

C. No Harm Found when Nurse Anesthetists Work Without

Supervision by Physicians .........................................................296

IV. OPT-OUT STATE REQUIREMENTS, STATUTES, AND REGULATIONS

VERSUS CURRENT SIMILAR INDIANA LAW ……………...........................298

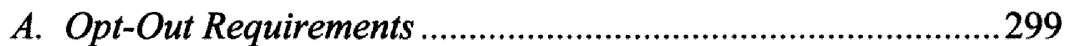

B. Challenged State Regulations or Opt-Out Decisions ..............300

1. State Law Challenges............................................................300

C. Similarly Situated Opt-Out States Contrasted to Indiana.........306

1. Rural Setting and Hospital Analysis ....................................306

2. Statutory or Code Regulation Comparison of Similarly

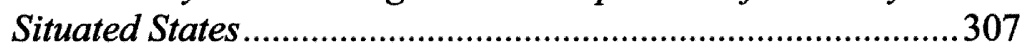

V. PROBLEMS ARISING IF INDIANA WERE TO OPT OUT OF PHYSICIAN

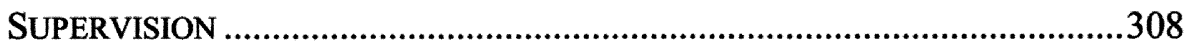

VI. SOLUTIONS AND CONCLUSION: KEEP THE STATUS QUO REGARDING

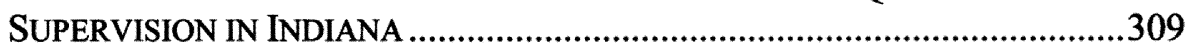

* J.D. Candidate, 2012, Indiana University Robert H. McKinney School of Law; B.S.B.A., 2008, Xavier University. 


\section{INTRODUCTION}

Nearly a decade ago, Dr. Barry Gleimer, an orthopedic surgeon in New Jersey, performed arthroscopic knee surgery on a twenty-eight year old man. ${ }^{1}$ Arthroscopy is a common surgical procedure where incisions are made, and a pencil-sized camera is inserted through those incisions after utilizing local, regional, or general anesthesia. ${ }^{2}$ Shortly after Dr. Gleimer performed the knee arthroscopy, the presiding nurse anesthetist-who at first failed to notice the patient turning blue from lack of oxygen-struggled to insert a breathing tube and quickly sought help from a nearby anesthesiologist. ${ }^{3}$ Due to the nurse anesthetist's inability to treat the patient during his desperate time, Dr. Gleimer's patient currently suffers from short-term memory loss. ${ }^{4}$ The resulting harm in the described procedure is conspicuous; however, the medical knowledge disparity between certified registered nurse anesthetists (CRNAs) and anesthesiologists, in cases such as Dr. Gleimer's, is far more noteworthy than the memory loss itself.

\section{A. The Issue}

Anesthesiologists and nurse anesthetists commonly work together in operating rooms to sedate patients and ease pain, but cooperation between the two groups ends once outside the hospital doors. ${ }^{5}$ For years, these two interconnected medical professions have fought a bitter political battle over who should be sedating patients, under whose supervision, and for what compensation. ${ }^{6}$ The battle intensified when, just before his term ended in 2001, President Bill Clinton, whose mother coincidently served as a nurse anesthetist for thirty-five years, wanted to remove supervision requirements. ${ }^{7}$ As a result, President Clinton approved a government rule giving more autonomy to nurse anesthetists. ${ }^{8}$ President Clinton's approval was in response to a 1997 proposal by the Health Care Financing Administration

1. Suzanne Sataline, Doctors Oppose a Nursing Push: New Jersey May Ease Sedation Oversight, WALL ST. J. (Oct. 23, 2010), http://online.wsj.com/article/SB10001424052 702304354104575568093578513032.html.

2. Knee Arthroscopy, AM. ACADEMY OF ORTHOPEDIC SURGEONS, AAOS.COM, http:// orthoinfo.aaos.org/topic.cfm?topic=a00299 (last updated Mar. 2010).

3. Sataline, supra note 1.

4. Sataline, supra note 1.

5. Personal Business; In This Doctor-vs.-Nurse Debate, Long, Deep Breaths, N.Y. TiMES (Oct. 8, 2000), http://www.nytimes.com/2000/10/08/business/personal-business-inthis-doctor-vs-nurse-debate-long-deep-breaths.html.

6. Id.; Rhonda Rowland, U.S. Ruling Expected in Bitter Anesthesia Battle, CNN.COM (May 16, 2001), http://articles.cnn.com/2001-05-16/health/anesthesia.debate_1_nurseanesthetists-physician-anesthesiologists-patient-safety?_s=PM:HEALTH.

7. Todd S. Purdum, Virginia Clinton Kelley, $7 \overline{0}$, President's Mother, Is Dead, N.Y. Times, Jan. 7, 1994, at A22; Amy Goldstein, HHS Delays Rule on Anesthesia Oversight; Clinton Measure Gave Nurses Autonomy, WASH. POST, May 18, 2001 , at A29.

8. Purdum, supra note 7; Goldstein, supra note 7. 
requesting that nurses be able to work by themselves, without doctor supervision, if allowed by state-specific law.

Upon Clinton's departure from office, the Bush administration delayed the Clinton-approved nurse autonomy rule and planned to write a new rule reverting back to the requirement that nurse anesthetists could only administer anesthesia when supervised by a doctor. ${ }^{10}$ The possible reversion sparked lobbying before Congress from former Senate majority leader, Robert J. Dole, and former Democratic representative, Tom Downey, on behalf of the anesthesiologists, while former House Speaker-designate, Bob Livingston, lobbied for the nurse-anesthetists. ${ }^{11}$ Ultimately, the anesthesiologists' representatives convinced President Bush of the possible safety hazards and risks involved with nurses independently administering anesthesia. ${ }^{12}$ However, both Tommy G. Thompson, who was the Secretary of Health and Human Services, and President George W. Bush were strong advocates for state autonomy; therefore, the Bush administration crafted a supervision rule giving governors the option to avoid the supervision requirement. $^{13}$

The Centers for Medicare and Medicaid Services' (CMS) final rule that was published in the Federal Register in November 2001 now allows state governors to opt out of reimbursement for CRNA activity, permitting CRNAs to practice without supervision if the opt-out is consistent with state law. ${ }^{14}$ Thus, under the CMS amended opt-out rule, patients, like Dr. Gleimer's arthroscopic knee patient, may not have physician supervised CRNAs in hospitals, ambulatory surgical centers, or critical access hospitals, ${ }^{15}$ which could lead to more severe injuries than just short-term memory loss due to the nurse and doctor knowledge disparity.

Interestingly, recent studies have challenged the knowledge gap between anesthesiologists and nurse anesthetists by concluding that there is not a significant difference in the quality of care administered by CRNAs as compared to anesthesiologists. ${ }^{16}$ After evaluating six years of Medicare data, two analysts at the Research Triangle Institute, an independent, nonprofit research institute, recently recommended that nurse anesthetists

9. Goldstein, supra note 7.

10. Goldstein, supra note 7; Rowland, supra note 6.

11. Goldstein, supra note 7.

12. Interview with Barry Glazer, Anesthesiologist, St. Francis Hospital \& Health Centers, in Indianapolis, Ind. (Jan. 28, 2011).

13. Goldstein, supra note 7 .

14. Medicare and Medicaid Programs; Hospital Conditions of Participation: Anesthesia Services, 66 Fed. Reg. 56,762, 56,763 (Nov. 13, 2001) (to be codified at 42 C.F.R. pts. $416,482,485)$.

15. Fact Sheet Concerning State Opt-Outs and November 13, 2001 CMS Rule, АM. ASS'N NURSE ANESTHETISTS, http://www.aana.com/advocacy/stategovernmentaffairs/Pages/ Fact-Sheet-Concerning-State-Opt-Outs.aspx (last updated Sept. 2010).

16. Editorial, Who Should Provide Anesthesia Care?, N. Y. TIMEs, Sept. 7, 2010, at A22. 
should be able to administer anesthesia without any surgeon or anesthesiologist supervision. ${ }^{17}$ Jerry Cromwell, the study's co-author and health economics fellow at the Research Triangle Institute, said, "[t]his study shows that patient safety is not compromised by the opt-out policy. Using nurse anesthetists more broadly could save on health care costs because they typically earn less than anesthesiologists."18 The study's recommendation is based on a lack of evidence to confirm that opting out of CRNA supervision has increased inpatient deaths or complications. ${ }^{1}$

Currently, sixteen states, including five of interest in this Note (California, Colorado, Iowa, Washington, and Wisconsin), have elected to opt out of reimbursement from CMS for nurse anesthetist activity as of October $2010 .^{20}$ As a result of the two most recent national studies dealing with CRNA safety and cost-effectiveness, state governors now have unequivocal evidence to persuade state medical and nursing boards to support a move to accept unsupervised nurses. ${ }^{21}$ Nevertheless, under the 2001 CMS amendment, governors still need to discern and balance the quality of care given to anesthesia patients, cost-effectiveness of not having physician supervision, and patient access in rural settings. ${ }^{22}$ Even if these factors are appraised, and opting out decreases state budgets, which is presently necessary in many states, the preemptive steps may not be enough to relieve patients of the risk of death or grave harm when a nurse anesthetist's treatment ability is challenged like that of the nurse in the aforementioned anecdote.

\section{B. Roadmap}

This Note discusses the CMS final rule allowing for unsupervised nurse anesthetists to administer anesthesia if their state of practice has opted out of Medicare reimbursement for such service. In order to facilitate a better understanding of the nurse anesthetist practice, Section II explains the history and development of the certified registered nurse anesthetist practice, sets out the educational requirements necessary for certification as a

17. Brian Dulisse \& Jerry Cromwell, No Harm Found When Nurse Anesthetists Work Without Supervision By Physicians, 28 HEALTH AFF. 1469, 1469 (2010); Press Release, RTI International, Nurse Anesthetists Working Without Doctor Supervision Provide Safe Care (Aug. 3, 2010), available at http://www.rti.org/page.cfm?objectid=19731DCD-C437DCAA-5DE995F6C1D7E6FC.

18. RTI International, supra note 17.

19. Dulisse \& Cromwell, supra note 17.

20. AM. ASS'N NURSE ANESTHETISTS, supra note 15.

21. Press Release, American Association of Nurse Anesthetists, Colorado Becomes 16th State to Opt Out of Physician Supervision Requirement for Nurse Anesthetist (Sept. 28, 2010), available at http://www.aana.com/newsandjournal/News/Pages/092810-Coloradobecomes-16th-State-to-Opt-Out.aspx.

22. See Press Release, American Association of Nurse Anesthetist, Iowa Becomes First State to Opt Out of Federal Anesthesia Requirement (Dec. 13, 2001), available at $\mathrm{http}: / / \mathrm{www}$. aana.com/news.aspx?id=714. 
CRNA, examines how nurse anesthetists are dealt with in Indiana, and provides CRNA reimbursement basics. Section III analyzes the major, recent studies proposing eliminating supervision of nurse anesthetists based on cost effectiveness and quality of care, while also providing the responses given by the American Society of Anesthesiologists to these controversial studies. Section IV introduces the requirements for a state to opt out of nurse anesthetist supervision and compares opt-out states' administrative code or statutes dealing with anesthesia regulation to Indiana's corresponding statutes. In particular, this section focuses on opt-out states' decisions that have been legally challenged for being inconsistent with state law, allowing for a prediction of the consistency of Indiana regulations if they were challenged. Also, in addition to looking at state law consistency issues, Section IV analogizes a CRNA scope of practice challenge to further highlight the disparity in anesthesiologist and nurse anesthetist training. Finally, Sections V and VI lay out problems that would arise if Indiana opted out of reimbursement and concludes Indiana should keep the status quo for nurse anesthetist supervision, or in the alternative should ramp up recognition or certification requirements of certified registered nurse anesthetists.

\section{HISTORY AND BACKGROUND OF CERTIFIED REGISTERED NURSE ANESTHETISTS}

In order to determine whether Indiana should opt out of nurse anesthetist supervision, an understanding of the development of the profession itself is essential. This section explains the practice of CRNAs in general, how the practice of nurse anesthetists developed, what educational and experience requirements are necessary to become certified as a nurse anesthetist, different methods of recognizing the nurse anesthetist practice, and, finally, offers rudimentary background on CRNA reimbursement.

\section{A. History and Development of the Nurse Anesthetist Practice}

Nurses, not anesthesiologists, were the first professional group to administer anesthesia in the United States, which led to the recognition in the late $1800 \mathrm{~s}$ of the first clinical nurse specialty, nurse anesthesia. ${ }^{23}$ For over 150 years, beginning with providing anesthesia to wounded soldiers during the Civil War, nurses have been administering anesthesia in the United States. $^{24}$ In addition to caring for soldiers, the development of the nurse

23. Am. Ass'N Nurse ANESThetists, Nurse ANesthetist: Advancing Patient SAFETY AND EXCELLENCE IN ANESTHESIA (2010), available at http://www.aana.com/ aboutus/Documents/legalissuesnap.pdf (citing the History of Nurse Anesthesia Practice section of the compilation).

24. Certified Registered Nurse Anesthetists (CRNAs) at a Glance, AM. Ass'N NURSE 
anesthetist occupation was also a response to surgeons' search for a solution to the high death rate during anesthesia in the late 1800 s, as medical residents wanted to observe surgery, not give undivided attention to the administration of anesthesia. ${ }^{25}$

By 1908, Cleveland-based surgeon George Crile asked a nurse, Agatha Hodgins, to become his anesthetist. ${ }^{26}$ Hodgins became an expert at administering anesthesia and began informally teaching others the anesthesia process, including English and French nurses who provided care to Allied Forces during World War I. ${ }^{27}$ Upon Hodgins's return from the war, she established the Lakeside Hospital School of Anesthesia in Cleveland, Ohio, a center that sent graduates across the country to provide nurse anesthesia care. $^{28}$ Soon thereafter, in 1931, Hodgins brought her alumnae to Cleveland and founded the National Association of Nurse Anesthetists, which in 1939 became the American Association of Nurse Anesthetists (AANA) and remains as such today. ${ }^{29}$ At present, greater than ninety percent of the nation's nurse anesthetists, of which over forty-one percent are men, are members of the AANA. ${ }^{30}$

Later, in 1956, the official credential of certified registered nurse anesthetist was born. ${ }^{31}$ Being recognized as one of the first specialties within nursing, CRNAs acted with a high level of independence, accountability and responsibility. ${ }^{32}$ According to the AANA, over 42,000 CRNAs across the country provide about thirty-two million anesthetics to patients each year. $^{33}$

\section{B. Educational/Certification Requirements and Statutory Recognition}

In order to become a CRNA and be able to provide anesthetics, special education and experience requirements must be met. ${ }^{34}$ These requirements include: $:^{35}$

1) Earning a Bachelor of Science in Nursing or other appropriate bac-

ANESTHETISTS, http://www.aana.com/ataglance.aspx (last visited Jan. 7, 2012).

25. AM. Ass'N NURSE ANESTHETISTS, supra note 23 (citing the History of Nurse Anesthesia Practice section of the compilation).

26. Id. (citing the History of Nurse Anesthesia Practice section of the compilation).

27. See The History of Nurse Anesthetists, AM. ASs'N NURSE ANESTHETISTS, $\mathrm{http}: / / \mathrm{www}$.anesthesiapatientsafety.com/na_glance/history.asp (last visited Jan. 7, 2011).

28. AM. Ass'N NURSE ANESTHETISTS, supra note 23 (citing the History of Nurse Anesthesia Practice section of the compilation).

29. Id. (citing the History of Nurse Anesthesia Practice section of the compilation).

30. AM. Ass'N NURSE ANESTHETISTS, supra note 24.

31. Id.

32. See Qualifications and Capabilities of the Certified Nurse Anesthetist, AM. Ass'N NURSE ANESTHETISTS, http://www.aana.com/ceandeducation/becomeacrna/Pages/ Qualifications-and-Capabilities-of-the-Certified-Registered-Nurse-Anesthetist-.aspx (last visited Jan. 8,2012 ).

33. Id.

34. Id.

35. AM. ASs'N NURSE ANESTHETISTS, supra note 24. 
calaureate degree;

2) Holding a current license as a registered nurse;

3) Serving at least one year of experience as a registered nurse in an acute care setting or facility;

4) Graduating with at least a master's degree from a Council on Accreditation of Nurse Anesthesia Educational Programs accredited nurse anesthesia educational program; ${ }^{36}$

5) Passing the national certification examination following graduation; and

6) Recertifying on a biennial basis, which requires a current nursing license, forty hours of continuing education, certification that the nurse has been engaged in anesthesia practice for the previous two years, and verification of no other problems that could adversely affect their practice of anesthesia. $^{37}$

Although these requirements are virtually standard nationwide, states may have different regulations or certifications that alter or eliminate such obligations. ${ }^{38}$ For example, Indiana and Michigan are the only two states that claim nurse anesthetists do not require additional certification in order to practice. 39 In Indiana, a CRNA "is properly certified by successfully completing the certification examination administered by the Council on Certification of Nurse Anesthetists or its predecessor." 40 The Indiana Association of Nurse Anesthetists interprets this certification provision as simply a definition, not a requirement to be additionally certified after passing the national examination by the Council on Certification of Nurse Anesthetists or other nationally recognized certifying body, as is required in all other states if a nurse wants to practice as a CRNA. ${ }^{41}$

Indiana nurse anesthetists are also distinct because "Indiana does not specify a specific method or process by which it authorizes nurse anesthetists to practice," 42 whereas CRNAs are a type of "advanced practice nurse" or "advanced registered nurse practitioner" in the majority of states in this country. $^{43}$ Under Indiana's Advance Practice Nurse Act, which deals with nurses obtaining additional skills through a specialized program to provide patient care in collaboration with the health care team, only nurse practi-

36. AM. Ass'N NURSE ANESTHETISTS, supra note 32.

37. Id.

38. See generally Requirements, AM. Ass'N NURSE ANESTHETISTs, http://www. aana.com/ceandeducation/becomeacrna/Pages/Requirements.aspx (last visited Jan. 8, 2012).

39. Id.

40. IND. CODE § 25-23-1-1.4 (2011).

41. AM. ASS'N NURSE ANESTHETISTS, supra note 38.

42. AM. ASS'N NURSE ANESTHETISTS, STATUTORY/Regulatory NURSE ANESTHETIST RECOGNITION, available at http://www.aana.com/advocacy/stategovernmentaffairs /Documents/recognition.pdf.

43. See id. 
tioners, nurse midwives, and clinical nurse specialists are mentioned. ${ }^{44} \mathrm{Be}-$ cause of their exclusion, nurse anesthetists believed the stricter collaboration requirements required of advance practice nurses would not apply to them, which would give them more autonomy to practice without supervision. ${ }^{45}$ However, under the Indiana Code, a CRNA may only administer anesthesia "[i]f the certified registered nurse anesthetist acts under the direction of and in the immediate presence of a physician." though Indiana has not statutorily established an advanced practice nurse label akin to most states, the scope of the nurse anesthetist practice in Indiana is still collaborative due to the supervision requirement.

Although any type of physician may collaborate with nurse anesthetists while the nurse sedates patients, much of the time CRNAs and anesthesiologists work closely together in operating rooms to administer anesthesia. ${ }^{47}$ The American Society of Anesthesiologists (ASA) "believes that nurse anesthetists are qualified to perform some, but not all, of these services [that an anesthesiologist can perform], and only under the supervision of a physician, preferably an anesthesiologist."48 This sentiment is often rooted in the differing educational and training requirements of the two disciplines, with anesthesiologists believing their profession is prepared to make sudden medical judgments that nurse anesthetists never learn in their curriculum. ${ }^{49}$ While a nurse anesthetist must gain a master's degree that usually takes two to three years (in addition to four years of nursing undergraduate work), anesthesiologists must complete twelve years of formal schooling, including: ${ }^{50}$

four years of science-intensive pre-medical undergraduate education; four years of medical school in which the individual gains knowledge of the fundamental science of the human condition (biochemistry, biophysics, anatomy, pharmacology, physiology, and pathology) and receives extensive clinical instruction and experience in medical diagnosis and therapy; and four years of residency training that includes one year

44. 848 IND. ADMIN. CODE 4-2-1 (2011); 848 IND. ADMIN. CODE 3-3-1 (2011); 848 IND. ADMIN. CODE 4-1-5 (2011).

45. Interview with Barry Glazer, Anesthesiologist, St. Francis Hospital \& Health Centers, in Indianapolis, Ind. (Jan. 28, 2011).

46. IND. CODE § 25-23-1-30 (2011).

47. Personal Business, supra note 5; see RTI International, supra note 17.

48. AM. Soc'y ANESTHESIOLOGISTS, The SCOPE OF Practice OF NURSE ANESTHETISTS 1 (2004), available at http://www.asahq.org/For-Members/Advocacy/ /media/ For\%20Members/Advocacy/Office $\% 200 \% 20$ Government $\% 20$ and $\% 20$ Legal\%20Affairs/ nurseanesscope.ashx.

49. See id.

50. See AM. Ass'N NURSE ANESTHETISTS, supra note 32; AM. Soc'Y ANESTHESIOLOGISTS, supra note 48, at 2. 
of clinical medicine, two years of clinical anesthesiology and one year of concentrated study and experience in connection with the most serious complications. $^{51}$

It is clear that educational requirements for anesthesiologists and nurse anesthetists differ, which is one reason why the "ASA opposes the independent practice of nurse anesthetists and views legislation and regulations designed to grant independent practice authority . . . as efforts to confer a medical degree by political means rather than by educational means." 52 Regardless of the ASA's contradicting view on nurse anesthetists' independence, state governors are given the authority to "confer" more power to nurse anesthetists, despite educational differences, based on the November 2001 CMS rule. ${ }^{53}$

\section{Reimbursement of CRNA Service}

Government programs, along with public and private health plans, provide reimbursement to CRNAs for performing anesthesia to patients. ${ }^{54}$ Medicare, a health plan for senior citizens and individuals with certain disabilities, is the largest program for reimbursement directly to CRNAs. ${ }^{55}$ Medicare uses a formula to determine reimbursement amounts: the sum of base units (which describe the complexity of the anesthesia procedure) and time units (where fifteen minutes equals one unit) multiplied by a conversion factor (in dollars). ${ }^{56}$ In addition to CRNA reimbursement, anesthesiologists can be paid under Medicare for directing administration of anesthesia, but only when certain conditions are met. ${ }^{57}$ Under the Tax Equity and Fiscal Responsibility Act of 1982 (TEFRA), an anesthesiologist must carry out the following conditions in each case in order to be reimbursed under a claim for directing anesthesia: ${ }^{58}$

1) Performance of a pre-anesthetic examination and evaluation; ${ }^{59}$

2) Preparation of an anesthesia plan; ${ }^{60}$

51. AM. SOC'Y ANESTHESIOLOGISTS, supra note 48, at 2.

52. Id. at 7 .

53. See American Association of Nurse Anesthetists, supra note 21; Hospital Conditions of Participation: Anesthesia Services, 66 Fed. Reg. 56,762, 56,763 (Nov. 13, 2001) (to be codified at 42 C.F.R. pts. $416,482,485$ ) (citing the governor's ability to exercise the exemption so physician supervision is not required).

54. AM. Ass'N NURSE ANESTHETISTS, supra note 23 (citing Reimbursement of CRNA Services section of the compilation).

55. Id. (citing Reimbursement of CRNA Services section of the compilation).

56. Id. (citing Reimbursement of CRNA Services section of the compilation).

57. Id. (citing Reimbursement of CRNA Services section of the compilation).

58. AM. SOC'Y ANESTHESIOLOGISTS, supra note 48, at 9-10.

59. Id. at 9.

60. Id. 
3) Personal participation in the most demanding parts in the anesthesia plan, most importantly induction and emergence; ${ }^{61}$

4) Assurance that a qualified anesthetist performed any part of the anesthesia plan not performed by himself or herself; ${ }^{62}$

5) Frequent monitoring of anesthesia administration; ${ }^{63}$

6) Physical presence in case of emergency or need for immediate diagnosis; ${ }^{64}$ and

7) Provide post-anesthesia care. ${ }^{65}$

Combining the reimbursement of nurse anesthetists and the conditions for anesthesiologist payment, Medicare Part B reimburses in different ways. ${ }^{66}$ For "non-medically directed CRNA services," when an anesthesiologist is not involved enough in a case to justify payment for medical direction, CRNAs are reimbursed one hundred percent of the Medicare fees according to the formula outlined above. ${ }^{67}$ When a physician fulfills the seven conditions under TEFRA, these so-called "medically directed CRNA services" are reimbursed according to the same Medicare formula, with fifty percent of the fee going to the directing anesthesiologist and the remaining fifty percent going to the CRNA. ${ }^{68}$ When an anesthesiologist oversees multiple anesthesia cases, or "medically supervised CRNA services," Medicare reimburses fifty percent of the fee to the CRNA and two or three base units to the anesthesiologist. ${ }^{69}$ If medically supervising, an anesthesiologist may be reimbursed for up to five simultaneous CRNA cases, as long as the seven TEFRA conditions are met. ${ }^{70}$

\section{ANALYSIS OF RECENT NURSE ANESTHETIST STUDIES}

\section{A. Anesthesiologist Direction and Patient Outcome}

The first important study of anesthesiology that is relevant to the comparison between anesthesiologists and nurse anesthetists was performed in $2000 .^{71}$ The study compared outcomes of Medicare surgery patients whose anesthesia was performed, or medically directed, by an anesthesiologist to

61. Id. at 10 .

62. Id.

63. Id.

64. Id.

65. Id. at 9-10. 324.

66. Tax Equity and Fiscal Responsibility Act of 1982, Pub. L. No. 97-248, 96 Stat.

67. AM. ASS'N NURSE ANESTHETISTS, supra note 23 (citing Reimbursement of CRNA Services section of the compilation).

68. Id. (citing Reimbursement of CRNA Services section of the compilation).

69. Id. (citing Reimbursement of CRNA Services section of the compilation).

70. Id. (citing Reimbursement of CRNA Services section of the compilation).

71. Jeffrey H. Silber et al., Anesthesiologist Direction and Patient Outcomes, 93 ANESTHESIOLOGY 152, 152 (2000). 
outcomes that were not. ${ }^{72}$ The study sought to determine if elderly patients' general and orthopedic surgical outcomes differed based on anesthesiologist involvement in anesthesia delivery. ${ }^{73}$ As mentioned above, when discussing reimbursement basics, in order to be directed, physicians or anesthesiologists must fulfill the seven criteria that allow them to bill under Medicare Part B. ${ }^{74}$ The study included 194,430 directed and 23,010 undirected cases in 245 Pennsylvania hospitals. ${ }^{75}$ The patient data studied was categorized into outcomes, which included death rate within thirty days of hospital admission, in-hospital complication rate (applying forty-one events defined by International Classification of Diseases), and the rate of death after complications (failure-to-rescue rate). ${ }^{76}$ In order to account for possible differences in hospital administration tactics and patient individuality, the study was adjusted using a list of eleven hospital and patient characteristics that standardized results. ${ }^{77}$

After analysis, the study found "higher mortality and failure-to-rescue rates for patients who underwent operations without medical direction by an anesthesiologist." 78 As shown below, percentages of death, complication, and failure-to-rescue were all higher in the study's undirected cases. ${ }^{79}$ The unadjusted results, based just on patient outcomes alone, were as follows. ${ }^{80}$

\begin{tabular}{|l|c|c|}
\hline Outcome & Uadirected Rate (\%) & $\begin{array}{c}\text { Direoted Rate (\%) } \\
\text { of } 194,430\end{array}$ \\
\hline Death & $4.53 \%$ & $3.41 \%$ \\
\hline Complication & $47.87 \%$ & $41.15 \%$ \\
\hline Failure-to-Rescue & $9.32 \%$ & $8.18 \%$ \\
\hline
\end{tabular}

Importantly, medical direction did not explain adjusted complication rates in Medicare patients because these rates are inadequate gauges of quality of care due to inaccurate coding and billing records. ${ }^{81}$ Nonetheless, after adjustment for patient and hospital characteristics, the odds ratios (the likelihood of an outcome occurring in the undirected group as opposed to the directed group) for death and failure-to-rescue were greater than 1 , at 1.08 and 1.10 respectively. ${ }^{82}$ The death and failure-to-rescue odds ratios correspond to 2.5 excess deaths per 1,000 patients and 6.9 excess failure-to-

72. Id.

73. Id. at 153 .

74. Id.

75. Id.

76. Id. at 154

77. Id. at 155; see also AM. Soc'Y ANESTHESIOLOGISTS, supra note 48, at 32-33.

78. Silber et al., supra note 71 , at 160.

79. Id. at 157 .

80. Id.

81. Id. at 160 .

82. Id. at 158; see also AM. Soc'Y ANESTHESIOLOGISTS, supra note 48, at 32-33. 
rescue deaths after complications per 1,000 patients when an anesthesiologist did not perform or direct the care. ${ }^{83}$

The results of this study may be easily skewed by hospital differences (for example, the number of beds over 200, the hospital's nurse-to-bed ratio, or the percentage of anesthesiology staff that is board certified) or from basing conclusions on elderly Medicare patients; however, even after adjusting for both of these factors, the effect of an anesthesiologist providing care was still shown to benefit patients. ${ }^{84}$ In concluding that mortality rates prior to and after complications were lower when anesthesiologists provided anesthesia, this study acknowledged a limitation of basing the findings on claims data and an inability to rule out the possibility conclusions could be based on differences in quality of direction, the lack of direction itself, or a combination of the two. ${ }^{85}$

\section{B. Cost Effectiveness Analysis of Anesthesia Providers}

Conversely, in a more recent 2010 study, the Lewin Group analyzed anesthesia administration models in order to determine if different anesthesia delivery models affect quality and cost-effectiveness of anesthesia services. $^{86}$ The study used "independent" CRNAs to refer to nurses who provide anesthesia but are not medically directed or supervised. ${ }^{87}$ As in other studies and costing models, the terms "medically directed" or "supervised" were used to define CRNAs who provide anesthesia under anesthesiologist oversight. ${ }^{88}$ The first issue considered in this study was quality of care, which is an important aspect of using alternative anesthesia delivery models. ${ }^{89}$

The authors of this study cite multiple reports that "have found no significant differences in rates of anesthesia complications or mortality between CRNAs and anesthesiologists or among delivery models for anesthesia that involve CRNAs, anesthesiologists, or both after controlling for other pertinent factors. ${ }^{, 90}$ However, impreciseness, the inability to distinguish between whether CRNAs or medical residents were being directed, and utilizing typical hospital practices instead of providers' specific practic-

83. Silber et al., supra note 71, at 158.

84. Id. at 152 .

85. Id.

86. Press Release, American Association of Nurse Anesthetist, Study Shows CRNAOnly Anesthesia Delivery Most Cost Effective (June 21, 2010), available at http:// www.aana.com $/$ news.aspx?id=26336\&terms $=$ lewin+study.

87. Paul F. Hogan et al., Cost Effectiveness Analysis of Anesthesia Providers, 28 NURSING ECON. 159, 160 (2010).

88. Id.

89. Id.

90. Id. 
es are all mentioned as limitations of the past-cited studies. ${ }^{91}$ Then, the authors conclude that it is "not surprising there are no studies that show a significant difference between CRNAs and anesthesiologists in patient outcomes."92 Although the authors identified multiple flaws in such studies, and the aforementioned Silber study found differences in outcomes based on supervision, the authors quickly concluded that there is no difference in quality of care between anesthesiologists and nurse anesthetists and thus sweepingly generalized a point of utmost concern to the ongoing battle between these two relevant professions.

In addition to literary data, the Ingenix national database that contained integrated medical and financial claims data from commercial payers in 2008 was studied by the Lewin Group. ${ }^{93}$ Out of 52,636 anesthesia claims that were reviewed, no complications arising from anesthesia were found. ${ }^{94}$ On top of Ingenix, the Healthcare Cost and Utilization Project Nationwide Inpatient Sample, which compiled information from about eight million U.S. community hospital stays, was also observed. ${ }^{95}$ Even though anesthesia provider information was not included in the hospital stay data, this study based its quality of care conclusion on the fact that the complication percentage for the representative sample was $0.12 \% .{ }^{96}$

If quality of care is assumed to be equal regardless of who administers anesthesia, as the authors of this study portray to their readers, then the best anesthesia delivery method for patients and facilities alike is the one that minimizes costs. ${ }^{97}$ In order to estimate costs and revenues under the different delivery models, a model was developed to simulate costs for each type of delivery. ${ }^{98}$ The user of the model must specify a number of key factors, such as: demand (number of patients seeking an operation in a day), characteristics of the anesthesia procedure (a base unit complexity number and the time required to do the procedure), and a payer distribution (noting the type of payment for each patient). ${ }^{99}$ Further, the cost estimation model used the salary or annual earnings of anesthesiologists and CRNAs to determine the final values. ${ }^{100}$ Results of the simulation when patient flow was sufficient to have four anesthesia procedures per day were as follows. ${ }^{101}$

\footnotetext{
91. Id.

92. Id. at 161 .

93. Id.

94. Id.

95. Id.

96. Id.

97. Id.

98. Id. at 162 .

99. Id.

100. Id.

101. Id. at 163 .
} 


\begin{tabular}{|c|c|}
\hline $\begin{array}{l}\text { Delivery Model (4 patioets per station per } \\
\text { day). }\end{array}$ & \\
\hline $\begin{array}{l}\text { Medical Direction } 1: 4 \text { (one anesthesi- } \\
\text { ologist per four CNRAs) }\end{array}$ & \\
\hline & \\
\hline & \\
\hline Süpervisory 1:6 (less & \\
\hline
\end{tabular}

Results of the simulation when patient flow was only two anesthesia procedures per day, when four were possible, were as follows. ${ }^{102}$

\begin{tabular}{|c|c|}
\hline $\begin{array}{l}\text { Delivery Model ( } 2 \text { patients per station per } \\
\text { day) }\end{array}$ & Yearly Profit \\
\hline $\begin{array}{l}\text { Medical Direction 1:4 (one anesthesi- } \\
\text { ologist per four CNRAs) }\end{array}$ & $\$-108,585$ \\
\hline Medical Direction 1:1 & $\$-3,128,421$ \\
\hline CRNA Only & $\$ 702,690$ \\
\hline $\begin{array}{l}\text { Supervisory 1:6 (less control than di- } \\
\text { rection) }\end{array}$ & $\$-546,867$ \\
\hline
\end{tabular}

This data showed the most cost-effective delivery model was CRNAs practicing alone, regardless of what level of demand is present. ${ }^{103}$ When demand was below average, which would include many rural areas of the United States, all delivery modes except CRNAs alone would require subsidies to be a viable option. ${ }^{104}$ Overall, this study hypothesized that CRNAs are less costly to train, provide higher revenues, and are interchangeable with anesthesiologists, as they can perform the same anesthesia services as medical doctors for less pay. ${ }^{105}$

After this bold conclusion regarding the cost effectiveness of nurse anesthetists was released, the American Society of Anesthesiologists was quick to respond. ${ }^{106}$ Dr. Alexander Hannenberg, President of the American Society of Anesthesiologist (ASA), offered seven reasons to question the cost-effectiveness study, including: ${ }^{107}$

1) The scope of service given by an anesthesiologist and a CRNA is

102. Id. at 164 .

103. Id. at 165 .

104. Id.

105. Id. at 168 .

106. Rob Kurtz, ASA President Offers 7 Reasons to Question Anesthesia CostContainment Study, BECKER's ASC REVIEW (July 1, 2010), http://www.beckersasc.com/ anesthesia/asa-president-offers-7-reasons-to-question-anesthesia-cost-containmentstudy.html.

107. Id. 
not the same because an anesthesiologist provides critical care medicine, pain management, and on-call coverage. ${ }^{108}$

2) The comparison of outcomes is invalid because the types of procedures done "solo" by CRNAs are of lower complexity, since patients, surgeons, and facilities prefer physician care for the more serious procedures. ${ }^{109}$

3) Only a few states are exempt from federal standards that make it necessary for a surgeon performing a procedure to supervise CRNAs; thus, defining CRNA services as "solo" is a misnomer. ${ }^{110}$

4) Medicare fees for using CRNAs and anesthesiologists are equal, so overall costs may increase if the CRNA calls for medical assistance or consultations. ${ }^{111}$

5) The wage estimations for CRNAs and anesthesiologists that are used assume equal work hours. Not only do the two professions not work the same hours, but also if CRNAs surpass the forty-hour week, employment costs are considerably increased, which is not the case with anesthesiologists. ${ }^{112}$

6) The Center for Disease Control concluded in 1980 that a comparative outcomes study could not be done based on the infrequency of major adverse anesthesia events. As thirty years have passed with fewer adverse events, the study is substantially less accurate. Also, the Ingenix database that was used is "fraudulent, discredited and outlawed." 113

7) In 2001, a study showed that seventy percent of all respondents would oppose a CRNA without supervision if a medical doctor could supervise the procedure at no additional cost; thus, patients tend to prefer anesthesiologists administering anesthesia. ${ }^{114}$.

Dr. Hannenberg closed by saying,

We [anesthesiologists] stand for access to safe and leading care for patients. We've gone through years and years of rigorous training in medical school, internships, residencies and fellowships. Anesthesiologists provide critical knowledge and expertise needed to keep total watch over the human body, to keep people stable and intervene when they are not. We are the leaders of anesthesia care teams which include CRNAs. The role of the anesthesiologist is to keep

108. Id.

109. Id.

110. Id.

111. Id.

112. Id.

113. Id.

114. Id. 
watch over a patient's vital health when he/she is at his/her most vulnerable. We take pride in this role each and every day. ${ }^{115}$

\section{No Harm Found when Nurse Anesthetists Work Without Supervision by Physicians}

In a 2010 article, researchers at the Research Triangle Institute, an independent, non-profit research institute, explored the change in the CMS supervision requirement by analyzing Medicare data for 1999-2005 in order to determine if the $2001 \mathrm{CMS}$ policy had a negative impact on patient outcomes. ${ }^{116}$ To show an effect on outcomes, the opt-out policy must actually change the way anesthesia is being provided and there has to be a difference in the outcomes linked to the new arrangement. ${ }^{117}$ The study identified three arrangements for anesthesia being administered: anesthesiologists practicing solo, certified registered nurse anesthetists practicing solo, and team anesthesia where nurses were directed or supervised. ${ }^{118}$

Studied data resulted in 741,518 surgical discharges, but only twothirds possessed anesthesia claims. The 481,440 hospitalizations that remained for analysis included 412,696 in non-opt-out states and 68,744 in opt-out states. ${ }^{119}$ Similar to the first study discussed in this Note, inpatient mortality, measured by checking discharge abstracts, and complications, detected by identifying seven possible problem indicators, were the two measured outcomes. ${ }^{120}$ To adjust for hospitals referring more difficult procedures to anesthesiologists, the statistics were controlled to deal with patient characteristics and procedure complexity. ${ }^{121}$

Resulting data showed that solo practicing nurse anesthetists did increase in opt-out states, ${ }^{122}$ which is exactly what the CMS rule allows after 2001; thus, the first conclusion of the study is not shocking. Next, the study presented results as follows of surgical inpatient mortality.

115. Id.

116. Dulisse \& Cromwell, supra note 17 , at $\mathbf{1 4 7 0 .}$

117. Id.

118. Id.

119. Id. at 1471; see also RTI International, supra note 17.

120. Dulisse \& Cromwell, supra note 17, at 1471.

121. Id. at 1471.

122. Id. at 1472 .

123. Id. at 1473. 


\begin{tabular}{|c|c|c|c|c|}
\hline \multirow{2}{*}{ Year } & \multicolumn{2}{|c|}{ 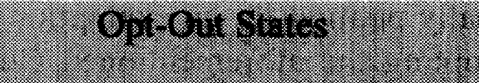 } & \multicolumn{2}{|c|}{ Nont Opt Ont Shotes } \\
\hline & CRNA Solo & Nora Dolo & Cratisto & WDis 80 \\
\hline 1999 & 1.76 & $=3.45$ & $=3.10$ & 3.50 \\
\hline 2000 & 2.50 & 3.67 & 3.16 & 3.21 \\
\hline 2001 & 3.01 & 2.80 & 3.54 & 3.68 \\
\hline 2002 & 2.26 & 2.72 & 3.09 & 3.44 \\
\hline 2003 & 2.49 & 2.39 & 3.21 & 3.58 \\
\hline 2004 & 1.86 & 3.82 & 2.84 & 3.20 \\
\hline 2005 & 2.03 & 1.32 & 2.34 & 2.76 \\
\hline
\end{tabular}

"In non-opt-out states, mortality rates for the [two] anesthesia arrangements followed a general downward trend throughout the seven-year period." 124 However, of interest is the "general downward trend" in opt-out states. After increasing from 1999 to 2001, the rate decreased from 2001 to $2005 .{ }^{125}$ Nevertheless, the rate did not significantly decrease between 2001 and 2005; rather, it increased almost a quarter from 2002 to 2003 (one year after CMS opt-out inception) and increased again from 2004 to 2005 . $^{126}$ Further, the study failed to note that the mortality rate was lower for solo MDA administration in three of five years after the supervision requirement was implemented; thus, allowing physicians to practice alone without CRNAs seems to be a safer alternative, regardless of the "decreasing trend" of CRNA solo practitioners. ${ }^{127}$

As stated earlier, linking the amended CMS rule to patient outcome changes "requires both that the proportion of surgical procedures for which certified registered nurse anesthetists alone provided anesthesia changed as a consequence of the policy change, and that the type of anesthesia provider affects the likelihood of in-hospital mortality or other adverse event."128 The data demonstrated neither of the two necessities. Instead, the data found that the proportion of anesthesia without anesthesiologist supervision increased five percentage points in all states, not just opt-out states. ${ }^{129}$ Nonetheless, declining mortality (or at least a downward trend according to the study) was normal despite the increasing number of solo nurse anesthetists in opt-out states. This mortality rate was even lower than solo anesthesiologists' mortality rate. ${ }^{130}$ These results led researchers to recommend that "CMS return to its original intention of allowing nurse anesthetists to work independently of surgeon or anesthesiologist supervision without re- 
quiring state governments to formally petition for an exemption."131 Thus, the researchers here advocate adopting the aforementioned Clinton nurse autonomy rule that was a response to the 1997 "original" intention of the Health Care Financing Administration. ${ }^{132}$

Like the cost-effectiveness study, the ASA did not allow this article to be published without comment. ${ }^{133}$ The ASA believes the AANA-sponsored paper "is an advocacy manifesto masquerading as science and does a disservice to the public. It makes dangerous public policy recommendations on the basis of inadequate data, flawed analysis and distorted facts." 134 The inadequate data stems from the fact that billing data was used to make forthright conclusions about doing away with supervision of nurse anesthetists. ${ }^{135}$ Such data does not distinguish between complications that happen during surgical procedures or due to anesthesia. ${ }^{136}$ Further, conditions are not noted as existing prior to surgery or as a result of anesthesia or surgery; thus, utilizing such data for a momentous hypothesis is flawed. ${ }^{137}$

In addition, if using the Institute of Medicine's current death per anesthesia mortality estimate based on 481,000 cases, the study would have discovered two anesthesia-related deaths, which is an unrealistic number on which to base mortality hypotheses. ${ }^{138}$ Lastly, ASA member and former nurse anesthetist, Ann C. Still, M.D., averred, "Having cared for patients as a CRNA and now as an anesthesiologist, I see daily how safe patient care requires a physician's training."139

\section{Opt-OUt State REQUiREMENTS, STATUTES, AND REgUlations VERSUS CURRENT SIMILAR INDIANA LAW}

As of October 2010, sixteen states have opted out of the federal supervision requirement since the enactment of the November 13, 2001, CMS Rule. ${ }^{140}$ Of particular importance in this Note are New Jersey, California, and Colorado because these states' nurse anesthetist regulations or opt-out decisions have been legally challenged. Scrutinizing the claims against each state in these cases will allow for a better prediction regarding the consistency or inconsistency of a possible opt out in Indiana as compared to

131. Id. at 1475 .

132. See generally id.

133. Press Release, American Society of Anesthesiologists, ASA Statement Regarding AANA-Sponsored Paper Published in Health Affairs, August 2010 (Aug. 5, 2010), available at $\mathrm{http}: / / \mathrm{www}$. asahq.org/news/asanews080510.htm.

134. Id.

135. Id.

136. Id.

137. Id.

138. Id.

139. Id.

140. AM. Ass'N NURSE ANESTHETISTS, supra note 15. 
nurse anesthetist regulations currently in place in opt-out states. Further, a more unproven analytic comparison of Indiana and the opt-out states of Iowa, Washington and Wisconsin based on geographic and demographic data bolsters the argument that Indiana is not similarly situated to necessitate opting out.

\section{A. Opt-Out Requirements}

In order to opt out of the federal supervision requirement, the state's governor must send a confirmation letter to CMS stating that he or she has consulted with the state's boards of medicine and nursing regarding issues related to patient access and quality of care of anesthesia, opting out is in the best interest of the state citizens, and the opt-out is consistent with state law. ${ }^{141}$ Upon the governor's submission of the attestation letter, the opt-out becomes immediately effective. ${ }^{142}$

In response to comments about the opt-out rule, CMS made clear that consultation between governors and state boards of medicine and nursing is required in order to include both sides in the opt-out discussion; however, "consultation" was purposefully not explicitly defined so that governors have maximum flexibility when making the opt-out decision. ${ }^{143}$ The fact that decisive authority remained in the hands of governors, who may not be scientifically endowed to review literature and make decisions, worried many commentators. ${ }^{144}$ CMS countered by pointing out that most scopeof-practice regulations for practitioners are made by states, thus enacting the opt-out rule to eliminate such regulations is no different. ${ }^{145}$

Another gray area is the interpretation of the "consistency with state laws" requirement, which produced the most comments when the opt-out rule was proposed. This requirement dealt with requests to outline steps in determining "consistency." 146 CMS recognized the differing opinions between anesthesiologists and nurse anesthetists on the state law issue (anesthesiologists say that only New Hampshire allows CRNAs to practice without supervision, while nurse anesthetists, based solely on nursing regu-

141. Medicare and Medicaid Programs; Hospital Conditions of Participation: Anesthesia Services, 66 Fed. Reg. 56,762, 56,763 (Nov. 13, 2001) (to be codified at 42 C.F.R. pts. $416,482,485)$.

142. AM. ASS'N NURSE ANESTHETISTS, supra note 15.

143. Medicare and Medicaid Programs; Hospital Conditions of Participation: Anesthesia Services, 66 Fed. Reg. 56,762, 56,763-64 (Nov. 13, 2001) (to be codified at 42 C.F.R. pts. $416,482,485)$.

144. Medicare and Medicaid Programs; Hospital Conditions of Participation: Anesthesia Services, 66 Fed. Reg. 56,762, 56,766 (Nov. 13, 2001) (to be codified at 42 C.F.R. pts. $416,482,485)$.

145. Medicare and Medicaid Programs; Hospital Conditions of Participation: Anesthesia Services, 66 Fed. Reg. 56,762, 56,766 (Nov. 13, 2001) (to be codified at 42 C.F.R. pts. $416,482,485)$.

146. Id. 
lations, argue that thirty-nine states do not have supervision requirements for CRNAs) but believed governors were the best suited to determine if opting out was consistent with state law. ${ }^{147}$ The bottom line is that "the governor's letter to the Administrator of CMS will be accepted on face value, with no independent CMS scrutiny or analysis of the governors' underlying rationale." 148

\section{B. Challenged State Regulations or Opt-Out Decisions}

\section{State Law Challenges}

\section{a. New Jersey office-setting nurse anesthetist supervision}

Although New Jersey is not an opt-out state, nurse anesthetist supervision requirements have been challenged both in the Appellate Division of the Superior Court and the New Jersey Supreme Court. ${ }^{49}$ In 1997, ironically, the same year that the Health Care Financing Administration proposed the nurse autonomy rule to President Clinton, ${ }^{150}$ the New Jersey State Board of Medical Examiners moved in the opposite direction by proposing, and later codifying, supervision regulations for anesthesia administered in a physician's office. ${ }^{151}$ When either general or regional anesthesia is administered by a CRNA in a New Jersey doctor's office, the CRNA must be "under the supervision" of a "physician privileged by a hospital or the Board" to give anesthesia. ${ }^{152}$ In addition, the monitoring physician must "be physically present and available to immediately diagnose and treat the patient in an emergency, without concurrent responsibilities to administer anesthesia or perform surgery, other than minor surgery."153

Once this regulation was adopted, the New Jersey Association of Nurse Anesthetists (NJANA) brought an appeal challenging the adoption, stating that it was without medical support, an arbitrary promulgation, and

147. Medicare and Medicaid Programs; Hospital Conditions of Participation: Anesthesia Services, 66 Fed. Reg. 56,762, 56,764-65 (Nov. 13, 2001) (to be codified at 42 C.F.R. pts. $416,482,485)$.

148. Medicare and Medicaid Programs; Hospital Conditions of Participation: Anesthesia Services, 66 Fed. Reg. 56,762, 56,766 (Nov. 13, 2001) (to be codified at 42 C.F.R. pts. $416,482,485)$.

149. Linda Dychkowski, It's Still "No!" for N.J. CRNAs, NuRSE.COM (Mar. 27, 2006), $\mathrm{http} / / /$ news.nurse.com/apps/pbcs.dll/article?AID=2006603270382.

150. Goldstein, supra note 7.

151. N.J. State Ass'n of Nurse Anesthetists v. N.J. State Bd. of Med. Exam'rs, 859 A.2d 1239, 1240 (N.J. Super. Ct. App. Div. 2004), affd sub nom. N.J. Ass'n of Nurse Anesthetists v. New Jersey State Bd. of Med. Exam'rs, 875 A.2d 247 (N.J. 2005).

152. N.J. ADMIN CODE $\S \S 13: 35-4 A .9(a)(1)$, (b) (2011).

153. N.J. ADMIN CODE § 13:35-4A.9(c) (2011); see also N.J. State Ass'n of Nurse Anesthetists, 859 A.2d at $1241-42$. 
an overextension of authority to regulate the nursing practice. ${ }^{154}$ However, the Medical Board "specifically may adopt rules to protect the health, safety and welfare of its licensees' patients and provide standards for the practice of medicine in New Jersey." 155 Regardless, the NJANA argued that studies, similar to those mentioned previously, demonstrate that death rates are the same among patients obtaining care from anesthesiologists as they are among those receiving care from nurse anesthetists working alone, making the supervision arbitrary. ${ }^{156}$ The Appellate Division of the Superior Court found persuasive the Medical Board's position that these studies deal with hospitals, where an anesthesiologist is usually present, instead of the relevant office setting where no such studies have been conducted. ${ }^{157}$

Moreover, the NJANA claimed that no factual basis existed for implementing this regulation; however, the court discarded this argument based on a belief that the Board "should not have to wait for bad results to require that its physicians meet higher standards in the administration of patient care." 158 Lastly, the NJANA argued that the Board was regulating the nursing profession, which the court concluded was incorrect, as only physicians who offered anesthesia in their offices were being regulated to ensure certain credential requirements were being met. ${ }^{159}$ Thus, the adoption of regulations by the New Jersey State Board of Medical Examiners was ultimately found to be lawful, and the CRNAs were required to adhere to supervision. 160

When the NJANA appealed the decision of the Appellate Division, the Supreme Court of New Jersey affirmed, concluding that the education and training of anesthesiologists better prepares them to "protect patients and to respond when complications occur."161 The court also found that there was insufficient evidence relative to available research to find that safety levels between doctors and CRNAs sedating patients are equal. ${ }^{162}$

\section{b. Louisiana scope of practice ruling}

Another non-opt-out state where CRNA activity has produced litigation is Louisiana. In 2005, the Louisiana State Board of Nursing (LSBN) implemented a policy permitting CRNAs to perform pain management,

154. N.J. State Ass'n of Nurse Anesthetists, 859 A.2d at 1241-42; Dychkowski, supra note 149.

155. In re N.J.A.C. 13:35-6.14, 501 A.2d 547, 550 (N.J. Super. Ct. App. Div. 1985).

156. N.J. State Ass'n of Nurse Anesthetists, 859 A.2d at 1244.

157. Id.

158. Id.

159. Id. at $1245-46$.

160. See id. at 1246.

161. N.J. Ass'n of Nurse Anesthetists v. N.J. State Bd. of Med. Exam'rs, 875 A.2d 247, 251 (N.J. 2005).

162. Id. at 250 . 
stating: ${ }^{163}$

[I]t is within the scope of practice for the CRNA to perform procedures under the direction and supervision of the physician involving the injection of local anesthetics, steroids and analgesics for pain management purposes, peripheral nerve blocks, epidural injections, and spinal facet joint injections when the CRNA can document education, training and experience in performing such procedures and has the knowledge, skills, and abilities to safely perform the procedures based on an order from the physician. ${ }^{164}$

Consequently, an anesthesiologist pain management group, Spine Diagnostics Center of Baton Rouge, filed suit seeking an injunction against the LSBN to enjoin the adoption of such a provision and prevent CRNAs from practicing pain management. ${ }^{165}$

Statutorily, CRNAs in Louisiana cannot perform anesthesia unless the anesthetics and ancillary services are administered "under the direction and supervision of a physician or dentist." ${ }^{166}$ Based on this statute alone, CRNAs may argue that pain management is an allowable anesthetic "ancillary service" they can perform under supervision. In the alternative, the CRNAs could contend that if prohibition of CRNAs performing pain management was intended by the legislature, it would have been included in the Louisiana anesthesia administration statute. ${ }^{167}$

The Louisiana Court of Appeal did not accept either of these possible CRNA arguments and affirmed the district court's judgment in favor of Spine Diagnostics Center based on scope of practice reasoning. ${ }^{168}$ The appellate decision concluded that "the statement issued by the LSBN expanded the scope of practice for CRNAs into an area where they have not traditionally practiced" and that "pain management is not within the scope of practice of a CRNA, but rather is solely the practice of medicine." 169 Multiple witnesses backed the finding. ${ }^{170}$ In particular, Dr. Frank Falco believed that practicing pain management without proper training could

163. Ga. Ass'n of Nurse ANESTHETists, Louisiana ApPellate Court Rules Against CRNA-Provided ChroniC PAIN MANAGEMENT 2 (2009) available at http://www.gana.org/documents/ LouisianaRulesAgainstCRNA.pdf; Spine Diagnostics Ctr. of Baton Rouge, Inc. v. La. State Bd. of Nursing, 4 So. 3d 854, 857 (La. Ct. App. 2008).

164. Spine Diagnostics Ctr. of Baton Rouge, Inc., 4 So. 3d at 857.

165. Id.

166. LA. REv. STAT. ANN. § 37:930 (2011).

167. Spine Diagnostics Ctr. of Baton Rouge, Inc., 4 So. $3 \mathrm{~d}$ at 863.

168. GA. ASS'N OF NURSE ANESTHETISTS, supra note 163.

169. Spine Diagnostics Ctr. of Baton Rouge, Inc., 4 So. $3 \mathrm{~d}$ at 867.

170. See id. at 865 . 
bring about to adverse consequences due to the varying complexity of each patient's pain management program. ${ }^{171}$

\section{c. California opt-out challenge}

Similar to the challenge by the nurse anesthetists in New Jersey, the California Society of Anesthesiologists brought suit against California Governor Arnold Schwarzenegger in February 2010 to dispute that his 2009 opt-out was inconsistent with state law in California. ${ }^{17}$ In California, CRNAs' scope of practice is broadly defined under the practice of nursing as: "those functions, including basic health care, that help people cope with difficulties in daily living that are associated with their actual or potential health or illness problems."173 Nurses can also administer medications and therapeutic agents, which have been universally understood to include anesthesia that are "ordered by and within the scope of licensure of a physician." 174 Nevertheless, the practice is somewhat limited because nothing defining the scope of nurse anesthetist practice in California confers the power of a nurse to practice medicine or surgery. ${ }^{175}$

With only a trial court order available thus far, and appellate review beginning on January 31,2011 , the arguments by the parties to the California opt-out challenge have to be deduced solely from the trial court's findings. ${ }^{76}$ The California Society of Anesthesiologists, like other anesthesiologists outlined in this Note, claimed that to be "ordered by" a physician is synonymous with being supervised. ${ }^{177}$ As a matter of fact, the ASA notes that "supervision or direction" can come in the "form of a physician's patient-specific order, request or prescription of treatment for anesthesia services."178 Thus, to order a nurse anesthetist to administer medication most assuredly would be supervision. ${ }^{179}$ However, the trial court did not accept this argument, simply dismissing it by stating "the plain meaning of the word 'ordered' is not 'supervised.",180 In addition, "Cali-

171. Id.

172. Summons on Complaint at 1, Cal. Soc'y of Anesthesiologists et al. v. Schwarzenegger, No. 10-510191 (Cal. Super. Ct. S.F. Cnty. Feb. 24, 2010).

173. CaL. Bus. \& Prof. CODE $\S 2725$ (b) (2011).

174. Cal. Bus. \& Prof. CoDE $\S 2725$ (b)(2) (2011).

175. CaL. Bus. \& Prof. Code $\$ 2833.5$ (2011).

176. Notice of Appeal at 1, Cal. Soc'y of Anesthesiologists et al. v. Schwarzenegger, No. 10-510191 (Cal. Super. Ct. S.F. Cnty. Jan. 31, 2011).

177. CRNA Scope of Practice Under California Law, ON YOUR BEHALF . . . Legislative AND PRACTICE AFFAIRS Division (Cal. Soc'y of Anesthesiologists, San Mateo, Cal.), Fall 2007, at 30, available at http://www.csahq.org/pdf/bulletin/issue_18/LPAD_ 56_3.pdf.

178. AM. SOC'Y ANESTHESIOLOGISTS, supra note 48, at 34.

179. See id.

180. Summary Judgment Order at 3, Cal. Soc'y of Anesthesiologists et al. v. Schwarzenegger, No. 10-510191 (Cal. Super. Ct. S.F. Cnty. Dec. 27, 2010). 
fornia law does not contain any explicit supervision requirement. Rather, at best, it is ambiguous on the supervision issue."181 An alternative argument of the Society was that administering anesthesia fits into the practice of medicine; therefore, giving CRNAs the ability to administer anesthesia without supervision contradicts California state law prohibiting nurses from practicing medicine. ${ }^{182}$ Like the anesthesiologists' supervision argument, the trial court did not find their alternative argument persuasive either. ${ }^{183}$

On the contrary, CRNAs in California quickly pointed out that in other provisions defining the practices of different nurse types the word "supervision" appears. ${ }^{184}$ For example, when dealing with a midwife, "the furnishing or ordering of drugs or devices by a certified nurse-midwife occurs under physician and surgeon supervision. For purposes of this section, no physician and surgeon shall supervise more than four certified nursemidwives at one time." If the legislature intended to include "supervision" for the nurse-midwives, then lawmakers would have included such wording for CRNAs if it were required. ${ }^{186}$

Based on the aforementioned arguments given by both sides, and accepting those offered by Governor Schwarzenegger and the California Association of Nurse Anesthetists as interveners, summary judgment upholding the state opt-out was granted. ${ }^{187}$ Therefore, the Superior Court of the State of California, County of San Francisco found that Governor Schwarzenegger's June 10, 2009 letter to CMS opting out of federal CRNA supervision requirements was not an abuse of his discretion. ${ }^{188}$

\section{d. Colorado opt-out challenge}

On September 28, 2010, the Colorado Society of Anesthesiologists brought suit to challenge Governor Bill Ritter's October 2010 opt-out decision. ${ }^{89}$ In their complaint the Colorado Society of Anesthesiologists prayed for a declaratory judgment and injunctive relief based on controversy about statutes dealing with the administration of anesthesia, making the opt-out inconsistent with state law. ${ }^{190}$ "On July 29, 2010, Governor Ritter

181. Id. at 2 .

182. See id. at 6; see also CAL. Bus. \& PROF. CODE $\$ 2833.5$ (2011).

183. Summary Judgment Order at 6, Cal. Soc'y of Anesthesiologists et al. v. Schwarzenegger, No. 10-510191 (Cal. Super. Ct. S.F. Cnty. Dec. 27, 2010).

184. See id. at 3.

185. CAL. Bus. \& Prof. Code $\S 2746.51$ (a)(4) (2011).

186. Summary Judgment Order at 3, Cal. Soc'y of Anesthesiologists et al. v. Schwarzenegger, No. 10-510191 (Cal. Super. Ct. S.F. Cnty. Dec. 27, 2010).

187. Id. at 7 .

188. Id. at 1 .

189. Hot Issues, CoLo. MED. Soc'y, http://www.cms.org/public-affairs/hot-issues/ \#Anesthesia\%200pt\%20Out (last visited Jan. 8, 2012).

190. Complaint at 2, Colo. Med. Soc'y v. Ritter, No. 33504523 (Denver Dist. Ct. Sept. $28,2010)$. 
issued a letter to the Colorado Medical Board and the Colorado Board of Nursing which declared his 'understanding' that 'the Colorado Nurse Practice Act allows CRNAs to practice without direct supervision from a physician." 191 According to an eight to five vote of the Colorado Medical Board, it was later determined that an opt-out was consistent with state law, sparking firm disagreement from the Colorado Society of Anesthesiologists. 192

In Colorado, nurse anesthetists are classified as advanced practice nurses, meaning that the nurse has specialized training and has applied to the board to be included in the advanced practice registry. ${ }^{193}$ The scope of practice comes under the definition of a delegated medical function, which means "an aspect of care that implements and is consistent with the medical plan as prescribed by a licensed or otherwise legally authorized physician . . . and is delegated to a registered professional nurse by a physician."194 For the purpose of defining delegated medical function, "medical plan" includes any written plan, verbal order, or standing order that authorizes specific action. 195

Using these statutory provisions, the Colorado Society of Anesthesiologists brought many of the same arguments as those in the California Society. ${ }^{196}$ For one, the Colorado anesthesiologists believe that delegated medical functions by nurse anesthetists must follow accepted practices; therefore, since administration of anesthesia is practicing medicine, supervision is required under accepted practices in Colorado. ${ }^{197}$ On the contrary, Governor Ritter and the nurse anesthetist association would likely make the same argument that was accepted in California: that supervision and an "order" are not synonymous terms. Thus, if a medical plan includes the nurse who administers the anesthesia, Colorado law would not explicitly require supervision of anesthetists. As with California, the language of the Colorado statute does not seem strong enough to overturn the deference given to the governor in opt-out decisions, but continuing to monitor this case as it moves through the Colorado court system is necessary.

\section{e. The Indiana Code language and precedent cases}

As mentioned earlier, a CRNA in Indiana can only perform anesthesia "if the certified registered nurse anesthetist acts under the direction of and

191. Id. at 3 .

192. Id.

193. CoLo. Rev. Stat. § 12-38-111.5(2) (2010).

194. Colo. REV. StaT. § 12-38-103(4) (2010).

195. Id.

196. See Complaint at 4-6, Colo. Med. Soc'y v. Ritter, No. 33504523 (Denver Dist. Ct. Sept. 28, 2010).

197. Colo. Rev. Stat. § 12-38-103(10)(a) (2010). 
in the immediate presence of a physician."198 Based on the foregoing challenges and the language of the Indiana Code, the Indiana Society of Anesthesiologists would have a much better argument that an opt-out is inconsistent with Indiana state law. Both California and Colorado use the word "order" when defining how a physician monitors a nurse anesthetist. ${ }^{199}$ Indiana's language is much stronger, as its Code requires nurses to be both under the direction and in the presence of a physician. It would be hard for the governor to claim, as in California and Colorado, that direct supervision of CRNAs is not explicitly defined by statute in Indiana. In addition, Indiana could use the New Jersey persuasive authority, even though it deals with office procedures, to bolster the argument that lawmakers have a factual basis to regulate CRNA scope of practice. By pointing to the weaknesses of the cost-effectiveness and Medicare data studies discussed earlier in this Note, Indiana anesthesiologists would also be able to show that, effectively, nurse anesthetists have not come up with an empirical study proving their practice is as safe or safer than anesthesiologists administering anesthesia because input data is flawed. ${ }^{200}$

In addition, Indiana has the ability to draw from the ruling by the Louisiana Appellate Division decision regarding scope of practice. Although the CMS opt-out provision does not expand CRNAs scope of practice responsibilities, the perspective given by Dr. Falco (finding CRNAs under qualified to perform chronic, complex pain management) bolsters the argument that Indiana should not opt out of supervision. ${ }^{201}$ Since CRNAs are not able to provide the pain management that anesthesiologists regularly administer, it is logically concluded that the aforementioned knowledge disparity between anesthesiologists and CRNAs is wide. Extending the gap to current CRNAs' scope of practice abilities shows that complications stemming from CRNAs' inability to assess "medical" situations are a compelling reason to not eliminate supervision requirements.

\section{Similarly Situated Opt-Out States Contrasted to Indiana}

\section{Rural Setting and Hospital Analysis}

Based on similar population and agriculture data in each state, Iowa,

198. IND. CODE $\S 25-23-1-30$ (2010).

199. See Colo. Rev. Stat. $§ 12-38-103(4)$ (2010); Cal. Bus. \& Prof. Code $\S$ 2725(b)(2)(2011).

200. See Press Release, American Society of Anesthesiologists, ASA Statement Regarding AANA-Sponsored Paper Published in Health Affairs, August 2010 (Aug. 5, 2010), available at $\mathrm{http} / / / \mathrm{www}$.asahq.org/For-the-Public-and-Media/Press-Room/News-Archives/ ASA-Statement-Regarding-AANA-Sponsored-Paper-Published-in-Health-Affairs.aspx; Kurtz, supra note 106.

201. See Spine Diagnostics Ctr. of Baton Rouge, Inc. v. La. State Bd. of Nursing, 4 So. 3d 854, 865 (La. Ct. App. 2008). 
Washington, and Wisconsin will adequately demonstrate the differences between three similarly situated, opt-out states as compared to Indiana. The population and farm acreage by state are as follows.

\begin{tabular}{|l|c|c|}
\hline Staterit & Population $^{202}$ & Number of Farms $^{203}$ \\
\hline Indiana & $6,377,000$ & 61,000 \\
\hline lowa & $3,003,000$ & 93,000 \\
\hline Washington & $6,549,000$ & 40,000 \\
\hline Wisconsin & $5,628,000$ & 78,000 \\
\hline
\end{tabular}

Aside from population and farmland, total land area of each of the four states is also of interest. Indiana is the smallest state in square miles of any of the four at 36,417 (compared to $56,273,71,298$, and 65,496 for Iowa, Washington, and Wisconsin respectively). ${ }^{204}$ Lastly, and likely most importantly, Indiana has the most non-federal, short term, acute care hospitals of any of the four mentioned states with 100 (compared to 40, 61, and 75 for Iowa, Washington, and Wisconsin respectively). ${ }^{205}$

This data shows Indiana as the second most agricultural, the second most populated, the smallest in terms of square mileage, and the densest in terms of hospitals when compared to similarly situated states of Iowa, Washington, and Wisconsin. A logical conclusion from these findings is that rural patient access is not as limited in Indiana as the other states because patients travel shorter distances to get to hospitals based on the presumption that there is a link between low square mileage and high number of hospitals in Indiana. Stemming from this analysis, an argument rejecting an Indiana opt-out is reasonable, as doctors are more readily available and in closer proximity to possible facilities that would need a physician to supervise CRNAs upon short notice. Overall, looking solely at rural area and hospital data, arguments against Indiana's patient access to anesthesia would crumble when compared to similarly situated opt-out states like Iowa, Washington, and Wisconsin, making an Indiana opt-out decision one the governor of Indiana need not contemplate due to anesthesia availability and patient access.

\section{Statutory or Code Regulation Comparison of Similarly Situated} States

In addition to a geographic and demographic analysis among the four

202. U.S. Census Bureau, Statistical Abstract of the United States: 2010, 21 tbl.12 (2010), available at $\mathrm{http} / / / \mathrm{www}$. census.gov/prod/2009pubs/10statab/pop.pdf.

203. Id. at 805 tbl.801.

204. Id. at 221 tbl.355.

205. Hospital Statistics by State, AMERICAN HOSPITALS DiRECTORY, http://www.ahd. com/state_statistics.html (last updated Apr. 18, 2011). 
states mentioned, a further look into statutory comparison will also be valuable in assessing why Indiana should not opt out of nurse anesthetist supervision. In Indiana, "[a] certified registered nurse anesthetist may administer anesthesia if the certified registered nurse anesthetist acts under the direction of and in the immediate presence of a physician." 206 On the contrary, Iowa hospital regulation only requires at a minimum that, "anesthesia services [are] provided under the direction of a qualified doctor of medicine or osteopathy."207 Like Iowa, Washington orders hospitals to adopt policies that "[d]efine the staff qualifications and oversight for administering each type of anesthesia in the hospital." 208 So, it is clear that some oversight is necessary in Iowa and Washington. However, to reiterate, Indiana is the only state that requires the "immediate presence" of a physician. 209

Iowa's and Washington's "direction" and "oversight" regulations are more lenient and could be construed as only requiring a physician to know a nurse anesthetist is independently administering anesthesia, so that in case of emergency they would be privy to the case. ${ }^{210}$ As a result, it is likely that anesthesiologists in both Iowa and Washington, like California, would not be able to prove that state law requires supervision. So, based on a geographic and demographic analysis, along with further statutory code comparisons, Indiana has two key differences from the opt-out states of Iowa, Washington, and Wisconsin before scrutinizing problems that may arise from an Indiana opt-out.

\section{Problems ARISING IF INDIANA WeRE to OPT OUT OF PHYSICIAN SUPERVISION}

If Indiana were to opt out of physician supervision, problems would arise stemming from certification, legislatures current opinion on CRNAs, and the inability to challenge the opt-out. Regarding certification, CMS stated that the Final Rule is flexible, and "[r]egarding patient safety, this final rule is consistent with our efforts to improve the quality of care furnished through Federal programs, while at the same time recognizing States' traditional domain in establishing professional licensure and scopeof-practice laws." 211 However, as stated above, Indiana does not recognize certification or require any further process to practice as a CRNA after the nurse passes the national board certification test. ${ }^{212}$ Such leniency in Indi-

206. IND. CODE ANN. § 25-23-1-30 (LexisNexis 2010).

207. IOWA ADMIN. CODE r. 481-51.28 (2010).

208. WASH. ADMIN. CODE § 246-320-241 (2010).

209. IND. CODE ANN. § 25-23-1-30 (LexisNexis 2010).

210. IOWA ADMIN. CODE r. 481-51.28 (2010); WASH. ADMIN. CODE § 246-320-241 (2010).

211. AM. Ass'N NURSE ANESTHETISTS, supra note 23 (citing the Legal Issues in Nurse Anesthesia Practice section of the compilation).

212. ASS'N NURSE ANESTHETISTS, supra note 38. 
ana may lead to less qualified CRNAs attempting to practice in the state, which in turn could lead to less favorable anesthesia outcomes than opt-out states that define CRNAs as advanced registered practice nurses and require licensing. ${ }^{213}$ With forty-eight states and the District of Columbia requiring certification beyond the national exam, Michigan and Indiana, two states that have not opted out of federal reimbursement for CRNA activity, remain in the clear minority with regard to officially recognizing nurse anesthetists to practice. 214

In addition to lagging behind in the certification department, Indiana also does not offer an accredited nurse anesthetist educational program. ${ }^{215}$ According to AANA, there are thirty-eight states, including the District of Columbia, that offer a total of one hundred twelve programs. ${ }^{216}$ Since Indiana lacks a nurse anesthesia program, quality control of in-state nurse anesthetists could potentially be an issue. If hospitals, critical access hospitals, and ambulatory surgery centers in Indiana are counting on educators from different states to train its nurse anesthetists, there is no way to educate CRNAs as to certain experiences, nuances, preferences, or regulations that are unique to Indiana. Thus, without upholding the supervision requirement in Indiana, physicians would, for all practical purposes, be allowing nurses trained by educators with differing scope of practice regulations in mind to administer anesthesia, which is not a patient friendly idea.

Lastly, Indiana Senator Patricia Miller carried a 2009 bill that attempted to include Indiana CRNAs as advanced registered practice nurses; however, the bill died. ${ }^{217}$ The death of this bill, which would have expanded the function of Indiana CRNAs, illustrates that Indiana lawmakers are not ready to hand the control of anesthesia in the state over to nurses. Such a feeling is consistent with a study conducted by The Terrance Group in 2001 which found that seventy percent of Medicare beneficiaries opposed the decision to drop the old requirement of supervision and allow nurse anesthetists to administer anesthesia without supervision. ${ }^{218}$

\section{SOLUTIONS AND CONCLUSION: KEEP THE STATUS QUO REGARDING SUPERVISION IN INDIANA}

After analyzing the available studies, data, and law, Indiana should come to the conclusion that the status quo of requiring physician supervi-

213. AM. Ass'N NURSE ANESTHETISTS, supra note 42.

214. ASS'N NURSE ANESTHETISTS, supra note 38.

215. See Becoming a CRNA: Accredited Programs, AM. Ass'N NURSE ANESTHETISTS, $\mathrm{http} / / / \mathrm{www} . a a n a . c o m /$ aanaaffiliates/accreditation/Pages/Accredited-Programs.aspx (last visited Jan. 12, 2012).

216. See id.

217. S.B. 190, 116th Gen. Assemb., Reg. Sess. (Ind. 2009).

218. The Tarrance Group, National Anesthesia Study III: A Survey of Public OPINION ATTITUDES 3 (2001). 
sion of certified registered nurse anesthetists should be upheld. For one, physician supervision of CRNAs allows for a more risk-averse, patient preferred anesthesia care. ${ }^{219}$ Even though administration of anesthesia is about fifty times safer than it was thirty years ago due to better technology and practice standards, death is still possible. ${ }^{220}$ Measures taken to increase the likelihood of saving a human life is undeniably a reason to uphold supervision requirements. Secondly, potential financial costs increase more if physician consultation is needed when a nurse anesthetist is allowed to administer unsupervised care, and something goes wrong. In the current, poor economic times, changing requirements may also increase costs. When one of the opt-out provision's cornerstone arguments is costeffectiveness, is not a sound decision if the state government is to be looking out for the best interests of Indiana citizens.

Nonetheless, if the decision to opt out of physician supervision is made in Indiana, the state should take action to further certify CRNAs apart from the national accreditation test that one must take to practice as a nurse anesthetist. However, in order to effectively certify and educate Indiana nurse anesthetists, the state must invest in a nurse anesthetist education program. Only by requiring state recognition to practice and investing in an education program can Indiana ensure nurse anesthetist procedures are as safe as possible when nurses are unsupervised.

As presented in the Introduction to this Note, Dr. Gleimer's twentyeight year old arthroscopy patient is a prime example of why a medical doctor needs to be present when a nurse anesthetist administers anesthesia. Dr. Carol Bannister, a former CRNA and current anesthesiologist, said that many times "[she] felt very much on thin ice," as a nurse anesthetist and that it frightens her to think about being unsupervised during her time as a nurse. ${ }^{221}$ Overall, Dr. Gleimer said it best himself: "We've all been in the $\mathrm{OR}$, when a nurse anesthetist reaches the end of her ability to treat the patient .... At that point, she hollers for an anesthesiologist to get her out of deep water."222 Indiana can avoid this "thin ice" and "deep water" if they keep the physician supervision requirement required to gain Medicare reimbursement for CRNA activity, or in the alternative take preemptive measures to certify and educate future nurse anesthetists.

219. Id.

220. AM. AsS'N NURSE ANESTHETISTS, supra note 23 (citing Quality of Nurse Anesthesia Practice section of the compilation).

221. Rowland, supra note 6.

222. Sataline, supra note 1 (internal quotation marks omitted). 